\title{
Clomiphene citrate alone versus combined metformin and clomiphene citrate versus combined metformin and clomiphene citrate and drilling versus metformin alone in infertile Indian women with PCOS: a prospective cross-sectional study
}

\author{
Bhavesh B. Airao, Parikshit J. Savalia*, Ranjeet V. Chaudhary
}

Department of Obstetrics and Gynecology, C. U. Shah Medical College, Surendranagar, Gujarat, India

Received: 28 January 2018

Accepted: 28 February 2018

\author{
*Correspondence: \\ Dr. Parikshit J Savalia, \\ E-mail: pjsavalia@gmail.com
}

Copyright: () the author(s), publisher and licensee Medip Academy. This is an open-access article distributed under the terms of the Creative Commons Attribution Non-Commercial License, which permits unrestricted non-commercial use, distribution, and reproduction in any medium, provided the original work is properly cited.

\begin{abstract}
Background: Polycystic ovary syndrome (PCOS) is a common cause of infertility and is associated with chronic anovulation and hyperandrogenemia. With associated features like irregular menses, acne and hirsuitism. It is seen in approximately $6 \%$ of women in reproductive age group and is one of the most common reproductive abnormality and endocrinopathy. Clomiphene Citrate remains the mainstay of this disorder however addition of metformin to it has been known to improve ovulation and pregnancy. The aim and objectives of the present study were to diagnose the patients with PCOS out of all patients who present with complaints of infertility, to compare ovulation and conception rates with Clomiphene Citrate alone V/S Combined Metformin and Clomiphene Citrate V/S Combined Metformin and Clomiphene Citrate and Drilling V/S metformin alone in Infertile Indian Women with PCOS.

Methods: A total of 50 cases with PCOS, in women of age group between 20 to 35 years was studied from June 2017 to December 2017. All of them having chief complain of infertility. Endocrino-histologic correlation and laparoscopic evaluation was confirmed by history, clinical manifestations, USG, laboratory investigations (LH, FSH, Insulin levels etc.) and laparoscopy was done.

Results: After administration of Insulin sensitizing agent, Tab. Metformin, 500mg 1 TDS, in management of PCOS who have hyperinsulinemic insulin resistance, there was ovulation with regular menstrual cycles, followed by pregnancy and full term deliveries. Thus, metformin definitely has a role in treatment of PCOS.

Conclusions: Metformin down regulated the hyperstimulated reproductive axis and allows for reversal to normoandrogenic state. Hence adding metformin to CC leads to increased ovulatory and conception rates as compared to either of them alone. In cases of laproscopic ovarian drilling spontaneous pregnancy rates showed no statistically significant correlation between the degree of fall in AMH but the chances of successful conception may improve after Ovarian drilling.
\end{abstract}

Keywords: Clomiphene, Hyperinsulinemia, Infertility, Metformin, Ovarian drilling, Polycystic Ovarian Syndrome

\section{INTRODUCTION}

Polycystic ovary syndrome (PCOS) is a common cause of infertility and is associated with chronic anovulation and hyperandrogenemia. It affects up to $6 \%$ of women with reproductive age. ${ }^{1}$ Clomiphene citrate remains the firstline therapy for induction of ovulation in these women. Clomiphene resistance (i.e., failure to ovulate after receiving $150 \mathrm{mg} /$ day) remains a common problem and occurs in approximately $15 \%-40 \%$ in women with PCOS. ${ }^{2,3}$ 
Clomiphene citrate may have a negative effect on the cervical mucus and endometrium and is associated with a discrepancy between ovulation and conception rates., ${ }^{4,5}$ More than half of the women suffering with PCOS have variable degrees of insulin resistance. Hyperinsulinemia will lead to hyperandrogenism, which causes the signs and symptoms of PCOS. $^{6}$ Metformin which is a biguanide reduces ovarian androgen production and has been used to treat insulin resistance in women with PCOS. This may directly affect follicular development and inducing ovulation. According to many previous studies, addition of metformin to $\mathrm{CC}$ in the CC-resistant cases helps in achieving ovulation in $68.6 \%-77.7 \%$ of patients. ${ }^{7-10}$ Recent studies have demonstrated that $\mathrm{AMH}$ levels also tend to be high in PCOS and response to ovulation inducing agents are inversely proportional to the levels of AMH. ${ }^{11,12}$

Laparoscopic Ovarian Drilling (LOD) has been used as an option for management of the group of patients not responding to ovulation induction. The success of LOD too is unpredictable but it has been observed recently that patients with very high AMH levels respond better when the AMH levels reduce after LOD. It is also seen that patients with normal and low baseline AMH levels do not benefit from LOD possibly because it indicates low ovarian reserve.

The aim of prospective cross-sectional study is to compare and determine the efficacy of clomiphene citrate alone V/S combined metformin-CC V/S combined metformin-CC-Ovarian drilling $\mathrm{V} / \mathrm{S}$ metformin alone when administered in infertile Indian women with PCOS.

\section{METHODS}

A prospective cross-sectional study was done by using pre-tested pre structured validated questionnaires. over 50 cases in CU Shah medical college from June 2017 to December 2017. All females of reproductive age group between 20-35 group having complaints of primary and secondary infertility were included in the study. Remaining patients with normal fertility and patients of infertility other than confirmed cases of PCOD were excluded from the study.

All the cases having chief complain of infertility along with other complaints of oligomenorrhoea, secondary amenorrhea, DUB, obesity, acne and hirsutism. Endocrino-histologic correlation and laparoscopic evaluation was obtained by clinical manifestations, USG: Transabdominal/ Transvaginal, Laboratory investigations: (LH, FSH, LH/FSH, FBS with fasting insulin levels) and finally Laparoscopy in all cases and Ovarian drilling in selected cases.

All suspected cases of PCOD underwent ultrasound scan, LH/FSH ratio on 3rd day, AMH on day 2 and Insulin levels. All patients with $\mathrm{LH} / \mathrm{FSH}$ ratio $>1.5$ were subjected to diagnostic laparoscopic examination.
Patients with FBS/ fasting insulin levels < 4.5 were given metformin along with $\mathrm{CC}$ and patients with High levels of AMH underwent LOD and AMH levels were repeated 7 days post operation.

\section{RESULTS}

\section{Clomiphene citrate only}

A total of 50 cases were studied who had chief complain of infertility and they were treated. In these, 44 patients were given $50 \mathrm{mg}$ dose of Clomiphene Citrate from 3rd to 7 th day of cycle. We followed all the patients through ovulation study with USG. If they did not have ovulation, we gave $100 \mathrm{mg}$ dose of $\mathrm{CC}$ in next cycle. Even if no ovulation occurred then $150 \mathrm{mg} \mathrm{CC}$ for 5 days each regime was followed for 3 cycles.

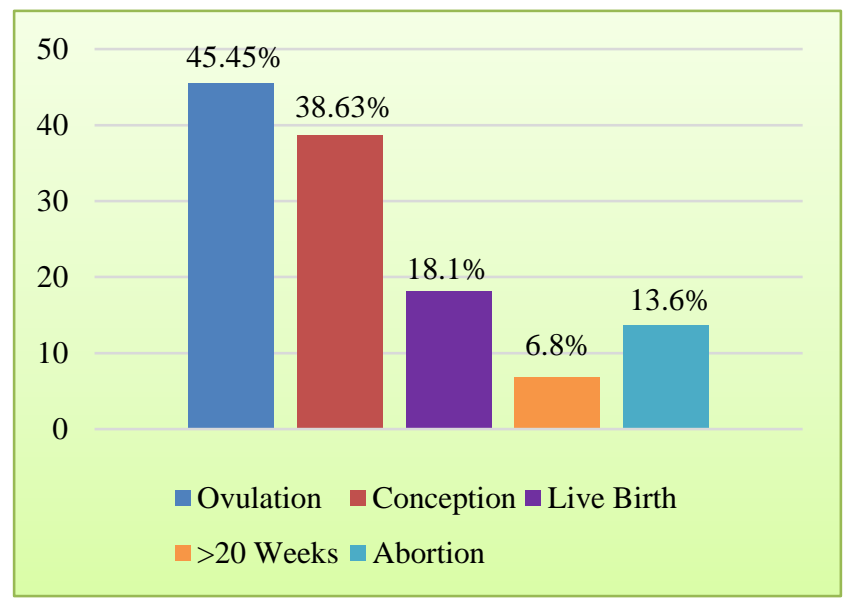

Figure 1: CC Alone.

\section{Clomiphene citrate + Metformin}

The 24 patients which remain anovulatory and did not respond to $\mathrm{CC}$ alone means resistance to $\mathrm{CC}$. So, in these patients, FBS/fasting Insulin levels were performed. Patients with FBS/fasting insulin levels $<4.5$ were taken for study. Tab.

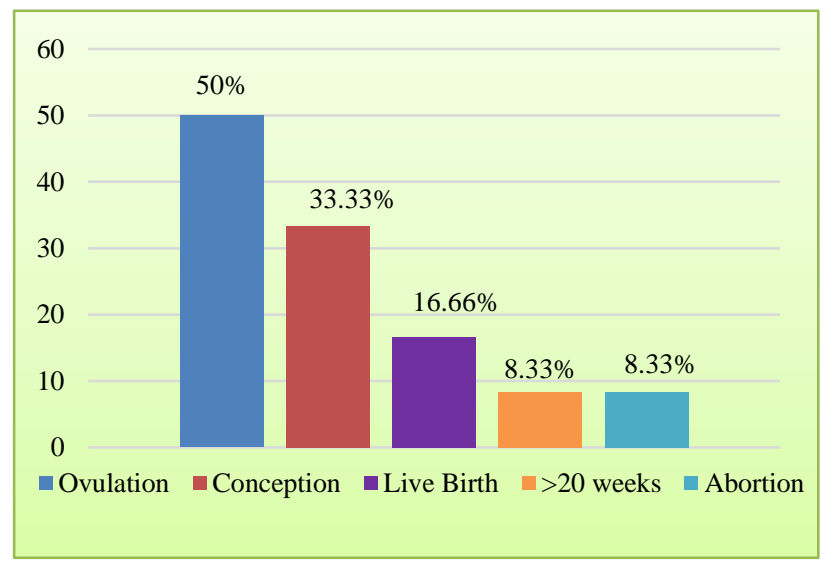

Figure 2: CC + Metformin. 
Metformin 500mg was given TDS for 6 cycles along with $\mathrm{CC}$ in 12 patients. These patients were obese with BMI $>25 \mathrm{~kg} / \mathrm{m}^{2}$.

\section{Clomiphebe citrate + Drilling + Metformin}

The other 12 patients who remained anovulatory, who were lean with normal BMI, and had high AMH levels, Laparoscopic drilling was performed. After that we waited for 3 cycles by giving CC $50 \mathrm{mg}$ from $3 \mathrm{rd}$ to 7 th day of menses. If no response was found, then Tab. Metformin 500mg TDS / day was given for 6 cycles.

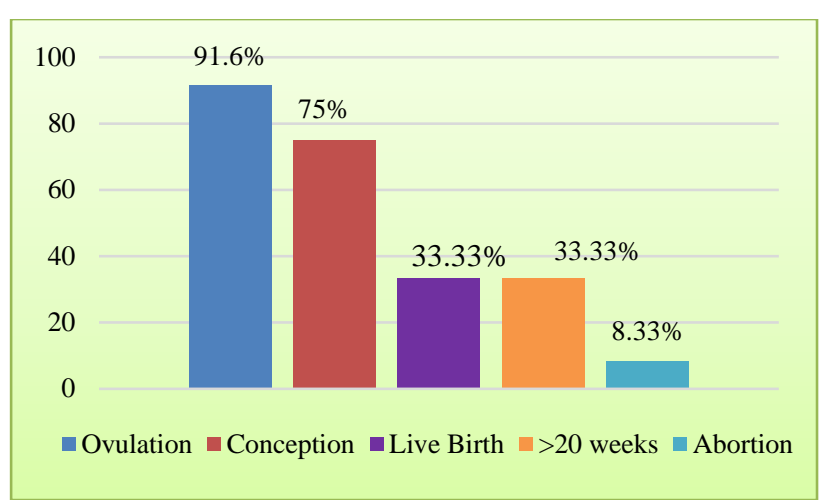

Figure 3: CC + Drilling + Metformin

Table 1: Modalities of treatment.

\begin{tabular}{|c|c|c|c|c|c|}
\hline Modalities of treatment & $\begin{array}{l}\text { Number of } \\
\text { patients }\end{array}$ & Ovulation & $\begin{array}{l}\text { Total live } \\
\text { births }\end{array}$ & $\begin{array}{l}\text { Total pregnancies }>20 \\
\text { weeks }\end{array}$ & $\begin{array}{l}\text { Total } \\
\text { abortions }\end{array}$ \\
\hline Clomiphene citrate only & 44 & 20 & 8 & 3 & 6 \\
\hline $\mathrm{CC}+$ Metformin & 12 & 10 & 4 & 2 & 2 \\
\hline $\begin{array}{l}\text { CC + Laparoscopic Drilling } \\
+ \text { Metformin }\end{array}$ & 12 & 11 & 4 & 4 & 1 \\
\hline Metformin only & 6 & 6 & 3 & 1 & 1 \\
\hline
\end{tabular}

\section{Metformin only}

In this study 6 patients out of 50 PCOD pts who had FBS/ fasting insulin ratio $<4.5$, and were obese, we started Tab. Metformin 500mg TDS/ day for 6 cycles. Once the patient conceived, Metformin 500mg, one tablet three times a day was continued till the delivery of baby. The study included 50 cases.

\section{Association between ovulation and live birth with various drug}

CHI SQUARE 0.216 with df $3(\mathrm{P}=0.97)$ - which is less than 0.05 so it shows the association is not significant. Association between ovulation and pregnancy $>20$ week with various drug. Chi square $=0.591$ with df (3) $(p=0.89)-$ which is less than 0.05 so it shows that the association is not significant. Association between ovulation and abortion with various drug. Chi square 0.603 with df (3) $(\mathrm{p}=0.89)$ which is less than 0.05 so it shows that the association is not significant.

\section{DISCUSSION}

Initially patients of PCOS were treated with $\mathrm{CC}$ and gonadotropins alone, but this mechanism has given a new direction towards its management with insulin sensitizing drugs that gave promising results and higher success rates of ovulation as well as pregnancy as compared with CC alone. ${ }^{13}$
A giant leap occurred when it was discovered that metformin was effective in ovulation induction in women. ${ }^{14}$ According to Cochrane review, metformin is superior to placebo for inducing ovulation in infertile women with PCOS with an odds ratio of 3.9 (confidence interval 2.3-6.7). ${ }^{15}$

This study has results comparable to various studies that have been carried out internationally. A study was carried out at Jordan showing the effects of metformin along with CC compared with placebo $\mathrm{CC}$, on the ovulation and pregnancy rates in CC-resistant women with PCOS. It was found that increased rates of ovulation $(50 \%$ versus $45.45 \%, \mathrm{P}<0.05)$ and pregnancy $(41.66 \%$ versus $38.63 \%$, $\mathrm{P}<0.05)$ in the metformin-CC group vs. placebo-CC controls. ${ }^{16}$ Overall ovulation rate in $\mathrm{CC}$ group of our study was comparable to certain studies, i.e., Batakan found $28.2 \%$ with $100 \mathrm{mg}$ of CC, Boostanfar et al., found $45 \%$ with CC dose of $150 \mathrm{mg}$, Memon et al. found $23 \%$ with $100 \mathrm{mg}$ of CC, and Lobo et al., found $32 \%$ with 200 $\mathrm{mg}$ of CC. ${ }^{17-20}$

In our study, regularity of menstrual cycle was found more in patients receiving metformin along with $\mathrm{CC}$, that concludes that metformin has an important role in regularization of menstrual cycle as concluded by Katsiki et al., Zain et al., and Pasquali and Gambineri. ${ }^{21-23}$

A controlled trial in India carried out previously that the metformin + $\mathrm{CC}$ resulted in higher rate of ovulation than $\mathrm{CC}$ alone group $(\mathrm{P}=0.0016)$. The pregnancy rate was $8 \%$ 
with CC and 24\% with metformin + CC group. Loss of appetite was found in $72 \%$ females of the study group while $18 \%$ had nausea and vomiting. Moreover, no case of hyperstimulation was seen in either group. Finally, it was concluded that this combination should be initiated early in the course of treatment. ${ }^{24}$

Vandermolen et al. tried to determine whether metformin treatment increased the ovulation and pregnancy rates in addition to $\mathrm{CC}$ in women with PCOS who were resistant to $\mathrm{CC}$ alone through a randomized, double-blind, and placebo-controlled trial. Higher rates of ovulation as well as conception in metformin $+\mathrm{CC}$ vs. placebo $+\mathrm{CC}$ group were found, i.e., (75\% vs. 27\%) and (55\% vs. $7 \%)$, respectively. ${ }^{13}$

Similar study carried out by Zain et al., compared metformin alone, $\mathrm{CC}$ alone, and metformin $+\mathrm{CC}$ in three groups of women with PCOS and found highest rate of ovulation $68.7 \%$ and conception $(21.1 \%)$ in metformin + $\mathrm{CC}$ group. They concluded that $\mathrm{CC}$ should be used as first line therapy in these women. ${ }^{22}$

Contrary to the study of Zain et al., Neveu et al., found nearly similar ovulation rates among PCOS females treated with metformin alone and metformin + CC group. Furthermore, conception rates were also not different in the three groups, i.e., metformin alone, $\mathrm{CC}$ alone, and combination group. It was suggested that metformin can be used first for ovulation induction in females with PCOS despite of their weight and insulin levels because of its efficacy and known safety profile. ${ }^{25}$

Contrary to studies of Neveu et al., and Zain et al, Jungheim and Odibo developed decision-analytic model by comparing the same three treatment strategies using probability estimates derived after reviewing literature and sensitivity analyses performed on the baseline assumptions, finalized that combination therapy should be the first line therapy. ${ }^{23,26}$.

\section{CONCLUSION}

The ovulatory rate with the metformin and $\mathrm{CC}$ combination was found to be significantly higher when compared with $\mathrm{CC}$ given alone $(\mathrm{P}=0.0016)$ in infertile PCOS subjects. The ovulatory rate was found to be increasing when $\mathrm{CC}$ of $150 \mathrm{mg}$ was given in combination with metformin for three cycles. The pregnancy rate was high with the $\mathrm{CC}$ and metformin combination when compared with $\mathrm{CC}$ alone and even in CC-resistance PCOS. Hence, this combination should be initiated early during treatment. In cases of laparoscopic ovarian drilling spontaneous pregnancy rates showed no statistically significant correlation between the degree of fall in $\mathrm{AMH}$ but the chances of successful conception possibly improved after LOD

Funding: No funding sources Conflict of interest: None declared
Ethical approval: The study was approved by the Institutional Ethics Committee

\section{REFERENCES}

1. Heard MJ, Pierce A, Carson SA, Buster JE. Pregnancies following use of metformin for ovulation induction in patients with polycystic ovary syndrome. Fertil Steril 2002;77(4):669-73.

2. National Collaborating Centre for Women's and Children's Health/National Institute for Clinical Excellence. Fertility: assessment and treatment for people with fertility problems. In:RCOGPress; 2004;11:57-8.

3. Beck JI, Boothroyd C, Proctor M, Farquhar C, Hughes E. Oral anti-oestrogens and medical adjuncts for subfertility associated with anovulation. Cochrane Database Syst Rev 2005;1(3):CD002249.

4. Randall JM, Templeton A. Cervical mucus score and in vitro sperm mucus interaction in spontaneous and CC citrate cycles. Fertil Steril 1991;56(3):465-8.

5. Nakamura Y, Ono M, Yoshida Y, Sugino N, Ueda $\mathrm{K}$, Kato $\mathrm{H}$. Effects of $\mathrm{CC}$ on the endometrial thickness and echogenic pattern of the endometrium. Fertil Steril 1997;67(2):256-60.

6. Legro RS, Castracane VD, Kauffman RP. Detecting insulin resistance in polycystic ovary syndrome: purposes and pitfalls. Obstet Gynecol Surv 2004;59(2):141-54.

7. Siebert TI, Kruger TF, Steyn DW, Nosarka S. Is the addition of metformin efficacious in the treatment clomiphene citrate-resistant patients with polycystic ovary syndrome? A structured literature review. Fertil Steril 2006;86(5):1432-7.

8. Malkawi HY, Qublan HS. The effect of metformin plus clomiphene citrate on ovulation and pregnancy rates in clomiphene-resistant women with polycystic ovary syndrome. Saudi Med J 2002;23(6):663-6.

9. Vandermolen DT, Ratts V, Evans WS, Stovall DW, Kauma SW, Nester JE. Metformin increases the ovulatory rate and pregnancy rate from clomiphene citrate in patient with polycystic ovary syndrome who is resistant to clomiphene citrate alone. Fertil Steril 2001;75(2):310-5.

10. Kocak M, Caliskan E, Simsir C, Haberal A. Metformin therapy improves ovulatory rates, cervical scores, and pregnancy rates in clomiphene citrateresistant women with polycystic ovary syndrome. Fertil Steril 2002;77(1):101-6.

11. Mumford SL, Legro RS, Diamond MP, Coutifaris C, Steiner AZ, Schlaff WD et al. Baseline AMH Level Associated With Ovulation Following Ovulation Induction in Women With Polycystic Ovary Syndrome. J Clin Endocrinol Metab. 2016;101(9):3288-96.

12. La Marca A, Sighinolfi G, Radi D, Argento C, Baraldi E, Artenisio AC et al. Anti-Mullerian hormone $(\mathrm{AMH})$ as a predictive marker in assisted reproductive technology (ART). Hum Reprod Update. 2010;16(2):113-30. 
13. Maria JI, Nestler JE. Insulin-lowering drugs in polycystic ovary syndrome. Obstet Gynecol Clin North Am. 2001;28(1):153-64

14. Vandermolen DT, Ratts VS, Evans WS, Stovall DW, Kauma SW, Nestler JE. Metformin increases the ovulatory rate and pregnancy rate from clomiphene citrate in patients with polycystic ovary syndrome who are resistant to clomiphene citrate alone. Fertil Steril. 2001;75(2):310-5.

15. Lord JM, Flight IH, Norman RJ. Metformin in polycystic ovary syndrome: Systematic review and meta-analysis. Br Med J. 2003;327(7421):951-3.

16. Malkawi HY, Qublan HS. The effect of metformin plus clomiphene citrate on ovulation and pregnancy rates in clomiphene-resistant women with polycystic ovary syndrome. Saudi Med J. 2002;23(6):663-6.

17. Labo RA, Granger LR, Davajan V, Mishell DR., Jr An extended regimen of clomiphene citrate in women unresponsive to standard therapy. Fertil Steril. 1982;37(6):462-6.

18. Batukan C, Baysal B. Metformin improves ovulation and pregnancy rates in patients with polycystic ovarian syndrome. Arch Gynecol Obstet. 2001;265(3):124-7.

19. Boostanfar R, Jain JK, Mishell DR, Jr, Paulson RJ. A prospective randomized trial comparing clomiphene citrate with tamoxifen citrate for ovulation induction. Fertil Steril. 2001;75(5):1024-6.

20. Memon Z, Karim N, Agha F. Effect of metformin versus clomiphene citrate on ovulation and conception rate in polycystic ovarian syndrome patients. J Basic Appl Sci. 2011;7:55-9.

21. Katsiki N, Georgiadou E, Hatzitolios AI. The role of insulin-sensitizing agents in the treatment of polycystic ovary syndrome. Drugs. 2009;69(11):1417-31.
22. Zain MM, Jamaluddin R, Ibrahim A, Norman RJ. Comparison of clomiphene citrate, metformin, or the combination of both for first-line ovulation induction, achievement of pregnancy, and live birth in Asian women with polycystic ovary syndrome: A randomized controlled trial. Fertil Steril. 2009;91(2):514-21.

23. Pasquali R, Gambineri A. Insulin-sensitizing agents in polycystic ovary syndrome. Eur $\mathrm{J}$ Endocrinol. 2006;154:763-75.

24. Dasari P, Pranahita GK. The efficacy of metformin and clomiphene citrate combination compared with clomiphene citrate alone for ovulation induction in infertile patients with PCOS. J Hum Reprod Sci. 2009;2(1):18-22.

25. Neveu N, Granger L, St-Michel P, Lavoie HB. Comparison of clomiphene citrate, metformin, or the combination of both for first-line ovulation induction and achievement of pregnancy in 154 women with polycystic ovary syndrome. Fertil Steril. 2007;87(1):113-20.

26. Jungheim ES, Odibo AO. Fertility treatment in women with polycystic ovary syndrome: A decision analysis of different oral ovulation induction agents. Fertil Steril. 2010;94(7):2659-64.

Cite this article as: Airao BB, Savalia PJ, Chaudhary $\mathrm{RV}$. Clomiphene citrate alone versus combined metformin and clomiphene citrate versus combined metformin and clomiphene citrate and drilling versus metformin alone in infertile Indian women with PCOS: a prospective cross-sectional study. Int J Reprod Contracept Obstet Gynecol 2018;7:1527-31. 